\title{
TRADIÇÃO DA GEOGRAFIA NOS ESTUDOS COSTEIROS
}

\author{
Msc. Flavia M. Lins-de-Barros \\ Doutoranda em Geografia da UFRJ - Laboratório de Geografia Marinha - PPGG / UFRJ \\ Ilha do Fundão - Cidade Universitária - Caixa Postal 68537 - CEP: 21941-972 - Rio de Janeiro - RJ - Brasil \\ Tel/fax:(21)2270-7773 /2535-1804 - flaviamlb@gmail.com
}

Prof. Dr. Dieter Muehe

dieter@ufrj.br

\begin{abstract}
RESUMO
A geografia tem uma forte tradição nos estudos costeiros desde, pelo menos, o século XVIII. Os estudos sobre a geografia física dos mares e geomorfologia costeira e, posteriormente, o interesse pelos aspectos sociais da zona costeira, demonstram a trajetória desta tradição. O presente artigo visa fazer uma retrospectiva desta tradição desde o nascimento do interesse científico pelo litoral, passando pelas abordagens física e social dos estudos do mar e da costa e, finalmente, chegando à uma análise da inserção dos geógrafos em publicações recentes. O breve histórico e os dados estatísticos debatidos tornam evidente a tradição geográfica nos estudos costeiros e, no contexto internacional, fica clara a posição de destaque desta ciência nas principais publicações sobre o tema.
\end{abstract}

Palavras-chave: Geografia costeira e marinha, tradição, gerenciamento costeiro integrado

\begin{abstract}
Geography has a strong tradition on coastal studies since, at least, the XVIII century. The studies of Marine Physical Geography and coastal geomorphology as also, recently, the interest on social aspects of the coastal zone, demonstrate the course of this tradition. This paper presents a retrospective of this tradition since the rise of the scientific interest about the littoral, passing to the physical and social approaches of the ocean and coastal studies and, finally, concluding with an analysis about the geographer's insertion in recent publications. The brief historical and statistical data discussed evidence the geographical tradition on coastal studies and, at the international context, the significant position of this science, reflected in two important scientific magazines.
\end{abstract}

Key words: Coastal geography, tradition, integrated costal zone management

RÉSUMÉ

La géographie a une grande tradition dans les études côtiers dès le XVIII siècle. Les études sur la géographie physique des mers et la géomorphologie côtière et depuis, l'intérêt pour les aspects sociaux de la zone côtière, démontrent la trajéctoire de cette tradition. Cet article vise a faire une rétrospective de cette tradition dès la naissance de l'intérêt scientifique sur le litoral, en passant pour les perspectives physique et sociale des études de la mer et de la zone côtière et, finalement, arrivant a une analyse de l'insertion des géographes dans les publications les plus récentes. Le brève historique e les dates statistiques déjà discutés montrent l'évidence de la tradition géographique dans les études côtiers et, dans le contexte international, devient claire la position détachée de cette science dans les plus importentes publications sur ce thème.

Mot Clés: Géographie Cotiêre et Maritime, Tradition, Amenagement Integré

\section{Introdução}

A geografia tem uma forte tradição nos estudos costeiros. Segundo AUGUSTINUS (1998), ao se fazer uma retrospectiva das disciplinas que tradicionalmente pesquisam a costa os geógrafos sempre estão presentes. Geógrafos físicos inserem-se principalmente no campo da geomorfologia e morfodinâmica, enquanto os estudos sobre a densidade populacional e a importância econômica das zonas costeiras atraem os geógrafos humanos (op. cit.). AUGUSTINUS (op. cit.) destaca ainda que em relação ao atual conceito de gerenciamento costeiro a geografia física e a geografia humana vêm tentando combinar seus conhecimentos visando dar os primeiros passos para a compreensão do gerenciamento costeiro integrado. 
O presente artigo procura fazer uma retrospectiva desta tradição geográfica nos estudos costeiros, desde a fase inicial do interesse científico pelo litoral até o momento atual, quando a interdisciplinaridade assume importância primordial nos estudos sobre gerenciamento costeiro integrado.

\section{O Nascimento do Interesse Científico pelo Litoral}

Os séculos XVII e XVIII são marcados pela predominância do sentimento de repulsa das praias e dos mares. A partir da leitura da bíblia sobre a gênese do mundo, surgem as teorias catastrofistas para explicação das formações costeiras (CORBIN, A. 1989). Pensadores como William Whiston, Burnet e Woodward concordavam que os oceanos, a irregularidade da linha de costa, as areias litorâneas e a disposição incompreensível dos recifes eram vestígios do dilúvio (op. cit.). No entanto, outras percepções sobre o mundo natural eram defendidas pelos sábios religiosos e poetas que exaltavam o prazer de se estar próximo ao mar. A chamada teologia natural propõe um sentido ao espetáculo da natureza e percebem o mundo exterior como uma representação divina. As praias e dunas não são entendidas como resultado da erosão, mas como elementos de uma arquitetura, edificada após o dilúvio (op. cit.).

Nesse momento de busca pela explicação da origem da Terra e da compreensão dos mistérios do mar, o litoral torna-se objeto de muitos estudos aplicados. Em 1694 o sueco Urban Hiärne realiza a primeira pesquisa científica sobre o recuo do mar através de um amplo questionário aplicado aos pescadores escandinavos cujas respostas foram publicadas entre 1702 e 1706 (CORBIN, A. 1989). Posteriormente surge a primeira mensuração das oscilações da linha de costa realizada por André Celsius (WEGMAN, 1977 apud CORBIN, A. 1989). A partir de 1724 André Celsius começa a investigar a emergência de alguns recifes, o abandono de canais e o relato de pescadores em diversas praias do mar Báltico. Em 1731 Celsius traçou linhas de controle sobre rochedos para posteriormente estimar o recuo do mar e em 1743 realizou a primeira medida científica do fenômeno sustentando a hipótese da diminuição dos oceanos. Posteriormente outros grandes estudiosos criaram hipóteses e fizeram observações e mensurações a respeito do recuo do mar. Em 1725 Marsigli publica o primeiro livro com a temática oceanográfica, intitulado Histoire Physique de la Mer. Alguns anos depois o geógrafo Philippe Buache expõe sua teoria sobre bacias terrestres e submarinas (CORBIN, A. 1989). Este geógrafo tornou-se conhecido pelas descobertas de mares e novos contornos entre a Ásia e a América do Norte registradas em um mapa de 1752. Outro marco histórico da oceanografia ocorre em 1807 quando Thomas Jefferson ordena a criação da US Coastal Survey (VALLEGA, A. 1998).

\section{A Tradição Geográfica nos Estudos Costeiros}

A importância das descobertas do geógrafo francês Phillipe Buache destacada acima já demonstra que a geografia está presente nos estudos costeiros e marinhos desde, pelo menos, o século XVIII. Após a institucionalização da ciência geográfica no século XIX, o estudo do litoral e dos oceanos continua a fazer parte dos temas estudados pela geografia. Importantes geógrafos como Ratzel e Vidal de La Blache escreveram sobre geografia marinha (VALLEGA, A., 1998). O primeiro, no capítulo XIII do livro Antropogeographie, trata das questões físicas das feições costeiras e dos mares assim como da relação entre o homem e o mar, destacando a navegação. Vidal de La Blache foi responsável por incentivar a criação do primeiro curso de geografia marinha o qual foi ministrado na Escola Naval de Brest, na França (op. cit.). No livro Princípios de Geografia Humana (1922), Vidal de la Blache apresenta um capítulo sobre o mar na parte que trata dos meios de circulação, abordando principalmente, como Ratzel, a navegação.

Os geógrafos apresentaram influência ainda maior nos estudos físicos da área costeira. KOMAR (1976), um dos mais conhecidos geólogos costeiros norte-americanos, afirma que os primeiros profissionais a estudarem as praias e as costas foram os geógrafos e geomorfólogos. Destacam-se como pioneiros nos estudos geomorfológicos costeiros e marinhos os geógrafos Cuchlaine A.M. King, Eric Bird, André Guilcher, Russel e Vsevelod P. Zenkovich. Seus interesses estavam em reconhecer e compreender a evolução das 
variadas formas costeiras: estudaram as mudanças de um determinado segmento de costa comparando configurações existentes com fotografias antigas, descreveram várias estruturas de praias e desenvolveram classificações de diferentes tipos de costas e suas seqüências evolutivas através do tempo (op. cit.). Merecem destaque os trabalhos e publicações destes e outros geógrafos e geomorfólogos de importância internacional como Johnson, autor do livro Shore Processes and Shoreline Development (1919), um dos clássicos mais citados na literatura; André Guilcher, renomado geógrafo francês com mais de 400 publicações sobre geografia marinha entre os anos de 1936 e 1981; o livro Coasts de Eric Bird (1969); e os livros Beaches and Coasts e Oceanography for Geographers, posteriormente desdobrado em dois: Introduction to Physical Oceanography e Introduction to Marine Geology end Geomorphology de autoria de Cuchlaine A.M. King.

\section{A Geografia e a Abordagem Social do Litoral}

Como foi destacado acima, ainda no começo do século XX geógrafos como Ratzel (1899), Vidal de La Blache (1922) e Camille Vallaux (1933) contribuíram com trabalhos sobre geografia marinha incluindo algumas análises do uso humano da costa (VALLEGA, 1998). No entanto tais abordagens se limitavam geralmente às questões de navegação e recursos marinhos. Segundo Pierre George (1967), o livro do geógrafo François Doumenge, intitulado Geografia dos Mares (1967), representa uma grande contribuição neste sentido pois:

...é uma apresentação absolutamente original e nova do mar como meio de vida, exploração e atividade humana. Nesse sentido, nada existia ainda em francês. E mesmo em língua estrangeira a documentação se achava singularmente espalhada. (Pierre George, 1967 p.3).

Em Geografia dos Mares François Doumenge aponta para o mar como fonte de riquezas explorando questões como a pesca, a agricultura do mar e os produtos minerais de origem marinha. Trata ainda do mar como elo entre os povos e como domínio de lazeres destacando o turismo costeiro e marítimo. Sobre este último tema o autor discute, entre outras coisas, o problema de conflitos entre o turismo e a exploração tradicional (pesca), questão esta muito debatida atualmente no âmbito do gerenciamento costeiro.

Mais recentemente cresce o número de pesquisas com abordagens econômica, social e política através de estudos sobre a vulnerabilidade sócio-econômica e o risco à erosão costeira; o planejamento urbano e o gerenciamento costeiro visando a adequada utilização dos recursos, a diminuição dos conflitos de uso na zona costeira e a preservação dos ecossistemas costeiros e marinhos. Neste sentido, vêm ganhando destaque geógrafos como James Mitchell que trata da questão da resposta da comunidade à erosão costeira no livro Community Response to Coastal Erossion: Individual and Colletive Adjustments to Hazard on the Atlantic Shore (1974); Dolan e Walker com artigos enfocando a questão da vulnerabilidade sócio-econômica; Ricketts através de pesquisas sobre a percepção da população em relação ao risco à erosão costeira; e Peter Augustinus, chefe da Comissão sobre Sistemas Costeiros da União Geográfica Internacional e responsável por diversos trabalhos na área de geografia marinha.

\section{A Importância das Publicações e Pesquisas Geográficas no Estudo Costeiro}

A partir da década de 1970 começam a surgir periódicos sobre estudos costeiros e a geografia tem importante influência neste processo. Entre os periódicos internacionais sobre pesquisa costeira destacase o Coastal Managment Journal, primeiro jornal publicado sobre gerenciamento costeiro, em 1972, sendo considerado um importante marco para a história do Gerenciamento Costeiro Integrado (SORENSEN, 2000). Este jornal é considerado pela editora um periódico da área de geografia. Destacase ainda o Journal of Coastal Research que teve sua origem na geografia e representa atualmente um dos principais veículos de divulgação científica sobre pesquisa costeira. São mencionados por Komar (1976) outros periódicos importantes neste campo como o Geographical Journal, Geography, Journal of 
Geomorphlogy e Zeitschrift für Geomorphologic.

No Brasil a importância dada aos estudos costeiros por geógrafos também é evidente. Merecem especial atenção alguns nomes como João Dias da Silveira, Azis Ab'Saber, Dieter Muehe, Marcus Polette e Antônio Robert de Moraes. O geógrafo João Dias Silveira apresentou no artigo Morfologia do Litoral (1964) a primeira macrocompartimentação do litoral brasileiro. Azis Ab'Saber, com ênfase na geomorfologia, dedicou especial atenção ao litoral do Brasil no recente livro intitulado O Litoral Brasileiro (2001) em que apresenta uma nova divisão do território brasileiro em diferentes regiões quanto às características da zona costeira. Deve-se apontar que foi este geógrafo quem proferiu a palestra inaugural do último Congresso de Oceanografia ocorrido em Itajaí, Santa Catarina (2004). Dieter Muehe apresenta uma linha de pesquisa também direcionada primordialmente à geomorfologia costeira e marinha, embora contemple aspectos voltados para a geografia e gerenciamento costeiros. Tal geógrafo é responsável pelo monitoramento de perfis de praia mais longo do Brasil. Sua importância nacional foi reconhecida em 2005 quando recebeu o prêmio Ciência Aplicada ao Mar pela Fundação Conrado Wessel. O geógrafo e oceanógrafo Marcus Polette merece destaque pela sua atuação na área de gerenciamento costeiro integrado sendo, atualmente, a principal referência desta temática no Brasil. Seus trabalhos têm uma abordagem bastante aplicada visando orientar políticas e programas de planejamento e gerenciamento costeiro. Marcus Polette foi responsável ainda pelo desenvolvimento do primeiro periódico publicado sobre o tema, a Revista Brasileira de Gerenciamento Costeiro Integrado. Finalmente, Antônio Robert de Moraes desenvolve pesquisas voltadas principalmente para a ocupação urbana das zonas costeiras, seus impactos e os conflitos de uso. Contribuiu com análises críticas sobre a gestão costeira no Brasil.

A valorização dada aos geógrafos nos estudos costeiros torna-se ainda mais clara com a convocação pelo Ministério do Meio Ambiente (MMA) de uma equipe de geógrafos da UFRJ e da USP para a realização do Macro Diagnóstico da Zona Costeira na escala da União (1996), um dos mais importantes levantamentos de dados que compõe o Plano Nacional de Gerenciamento Costeiro. A série intitulada Gerenciamento Costeiro publicada também pelo MMA é composta, em sua maioria, por livros de autoria de geógrafos.

\section{O Gerenciamento Costeiro Integrado e a Interdisciplinaridade}

Atualmente uma das temáticas mais estudadas no campo da zona costeira é o Gerenciamento Costeiro Integrado. Segundo diversos autores (FRENCH, 1997; KOMAR, 1976; POLETTE \& POGETTI SILVA, 2003; VALLEGA, 1998) a noção de gerenciamento costeiro tem sua origem, na década de 1960, quando estava voltada basicamente para as questões de erosão costeira. Para POLETTE \& POGETTI SILVA (op. cit.) as dificuldades encontradas ao longo da década de 1980 para implantação de programas de gerenciamento revelaram que a complexidade das zonas costeiras exigia uma noção de gerenciamento costeiro também mais complexa, ampla e integrada. A partir da década de 1980 começava a aparecer, então, o conceito atual de Gerenciamento Costeiro Integrado (GCI) que engloba desde questões relacionadas à preservação ambiental e dos recursos, até as questões sociais como o uso do solo, os conflitos entre diferentes atividades, entre outras.

Esta complexidade e abrangência das questões, bem como as problemáticas, geraram também um enorme crescimento do número de disciplinas interessadas na zona costeira. VALLEGA (1998) ressalta que nas décadas de 1960 e 1970 as principais disciplinas dedicadas ao gerenciamento costeiro eram a geologia e a geografia; na década de 1980 a abordagem ainda era uni-disciplinar, embora mais ampla atraindo a biologia, a ecologia e o direito; a partir de 1980 as abordagens tornam-se interdisciplinares e especialistas de outras áreas, como sociologia e planejamento urbano, integram a variedade de profissionais.

\section{A Inserção dos Geógrafos no Contexto Atual da Interdisciplinaridade}

Esta crescente atenção dada ao gerenciamento costeiro por profissionais das áreas de oceanografia, geologia, engenharia e economia se reflete no número de trabalhos publicados por estes nos dois últimos 
congressos da Associação Brasileira do Quaternário (ABEQUA). Desde 1987 tal congresso é realizado a cada dois anos. Em 2001, mais da metade dos trabalhos apresentados (174) correspondeu a investigações nas regiões costeiras, relacionadas às sessões temáticas da Evolução Costeira (117) e da Gestão e Gerenciamento Costeiro (57). Nesta última sessão temática, quase 30\% são trabalhos de autoria de geólogos, aproximadamente o mesmo número de trabalhos de oceanógrafos e apenas $10 \%$ são trabalhos realizados por geógrafos. Os restantes 30\% são de diversas outras áreas como hidrodinâmica, química, geodinâmica e arqueologia. Percebe-se com isso uma grande variedade de ciências estudando a temática da gestão costeira, o que ocorre novamente no congresso da ABEQUA realizado em 2003.

No quadro internacional, a estatística realizada sobre a procedência dos autores que publicaram em duas importantes revistas entre 2001 a 2005 também revela claramente esta interdisciplinaridade. No entanto, o número de geógrafos não é tão inexpressivo como no quadro nacional. Os periódicos analisados foram o Journal of Coastal Research, cuja abordagem é voltada principalmente para os processos físicos costeiros e a Ocean and Coastal Management, um dos principais periódicos internacionais direcionado para o gerenciamento costeiro e marinho. No primeiro caso foram selecionados 92 artigos com diferentes temáticas como morfodinâmica, erosão costeira, proteção costeira (obras), mudanças climáticas globais, variações do nível do mar, gerenciamento costeiro e impacto ambiental. O resultado mostrou que mais da metade dos autores (52\%) estão vinculados a instituições ou laboratórios interdisciplinares (ex.: laboratório de pesquisa costeira; estudos do meio ambiente; departamento de geociências). Excluindo-se tais autores, ganha destaque o número de trabalhos de geólogos (aproximadamente 34\% do total) seguido dos trabalhos de geógrafos, com mais de 19\% (tabela 1). Destaca-se ainda o campo da engenharia apresentando um número de autores muito próximo ao de geógrafos.

Tabela 1 - Procedência disciplinar dos artigos publicados no Journal of Coastal Research 2001 - 2005

\begin{tabular}{l|r} 
CAMPOS DISCIPLINARES & \multicolumn{1}{l}{$\%$} \\
\hline geologia & 34.60 \\
\hline geografia & 19.60 \\
engenharia & 18.80 \\
oceanografia & 7.80 \\
hidráulica & 7.00 \\
\hline ecologia & 3.14 \\
\hline climatologia/meteorologia & 8.66 \\
Total & 100.00
\end{tabular}

Entre os artigos voltados para a temática do gerenciamento costeiro e impactos ambientais, este quadro não é muito alterado, predominando autores da área de geologia, seguido de geógrafos e de engenheiros.

O periódico Ocean and Coastal Management apresenta-se ainda mais interdisciplinar com aproximadamente $70 \%$ dos autores vinculados a instituições sem definição disciplinar clara. É interessante notar ainda uma maior participação de áreas relacionadas à questão social como o direito e a antropologia. Além disso, a geologia e a engenharia perdem importância enquanto a oceanografia aparece com o maior número de trabalhos entre as disciplinas ( $22 \%$ do total de autores são da área oceanográfica). A geografia novamente apresenta o segundo maior número de autores, com aproximadamente $20 \%$, seguida de trabalhos com autores procedentes de departamentos de antropologia (tabela 2). Uma observação deve ser feita em relação aos trabalhos do instituto de arquitetura, visto que quatro dos cinco trabalhos nesta área têm como autor o geógrafo e vice-presidente da União Internacional de Geografia (UGI), Alberto 
Vallega. Porém, o autor se identifica como integrante do Instituto de Arquitetura, tendo sido utilizado como critério esta declaração. No entanto, caso os quatro artigos fossem considerados como de origem geográfica esta ciência apresentaria o maior número de artigos nesta revista para o período estudado, com mais de $30 \%$.

Tabela 2 - Procedência disciplinar dos artigos publicados no Ocean and Coastal Management 2001 - 2005

\begin{tabular}{ll} 
CAMPOS DISCIPLINARES & $\%$ \\
\hline oceanografia & 22 \\
\hline geografia & 19,5 \\
antropologia & 17 \\
ecologia & 12,2 \\
arquitetura & 12,2 \\
\hline direito & 7,32 \\
\hline geologia & 4,88 \\
engenharia & 2,4 \\
biologia & 2,4 \\
\hline total & 100 \\
\hline
\end{tabular}

A comparação estatística entre as duas revistas mostra um resultado interessante quanto à relação entre o tipo de abordagem de cada uma delas e as áreas disciplinares predominantes. Enquanto o Journal of Coastal Research, com trabalhos mais especializados nos processos físicos costeiros, apresenta como principais áreas as ciências exatas (geologia e engenharia têm destaque), a outra revista apresenta um enfoque no gerenciamento e as ciências humanas ganham importância. A geografia, talvez em função da sua interdisciplinaridade, própria da natureza desta ciência, se destaca em ambas as revistas.

\section{Considerações Finais}

O breve histórico e os dados estatísticos debatidos apontaram uma tendência, no contexto atual, de interdisciplinaridade dos estudos costeiros tanto no Brasil como nos estudos internacionais. No entanto, é preciso olhar tal tendência de maneira crítica questionando até que ponto os profissionais destes diferentes campos disciplinares possuem bases teóricas, conceituais e metodológicas para abordar de forma integrada e com a devida complexidade as diversas dimensões físicas, sociais, econômicas e políticas envolvidas no conceito de gerenciamento costeiro integrado. No caso brasileiro, é surpreendente o pequeno número de trabalhos da área da geografia em um dos principais congressos nacionais que trata da zona costeira. Desta forma, tendo em vista a sua tradição nos estudos costeiros e a sua abordagem integrada, aponta-se aqui a necessidade de uma maior participação do geógrafo nos estudos marinho e costeiro visando demonstrar como a riqueza interdisciplinar desta ciência a torna especialmente importante, não apenas no campo da geomorfologia costeira, como também nos estudos teóricos e aplicados de gerenciamento. Neste sentido, VALLEGA (1998) afirma que a "bagagem" teórico metodológica da geografia regional fornece elementos relevantes, visto que o desenvolvimento do gerenciamento costeiro, por apresentar como característica primordial uma visão holística, deve ser considerado como um caso especial do desenvolvimento regional. O autor completa que o gerenciamento costeiro é uma das áreas que permite à geografia demonstrar sua habilidade em lidar com realidades espaciais complexas (op. cit.). Deve-se apontar, no entanto, que, como ressalta AUGUSTINUS (1998) é um erro pensar que os geógrafos isoladamente são capazes de estabelecer uma estrutura científica para o gerenciamento costeiro integrado visto que, para tanto, é preciso a integração de diversas disciplinas. 


\section{Referência Bibliográfica}

AUGUSTINUS, P.G.E.F. Coastal Geography vis-à-vis the global change approach and coastal sustainable development. In: A. VALLEGA, P.G.E.F AUGUSTINUS \& H.D. SMITH (ed.). Geography. Oceans and coasts towards sustainable development. Franco Angeli, 1998.

CORBIN, A. O território do Vazio. A praia e o imaginário ocidental. Tradução Paulo Neves. São Paulo: Ed. Companhia das Letras, 1989.

DOUMENGE, F. Geografia dos Mares. São Paulo: Difusão Européia Livros, 1967.

FRENCH, P. Coastal and Estuarine Management. London; New York: Routledge environmental management series, 1997.

GEORGE, P. prefácio. In: DOUMENGE, F. Geografia dos Mares. São Paulo: Difusão Européia Livro, 1967.

KOMAR, P. Beach Process and Sedimentation. Prentice-Hall, INC., Englewood Cliffs, New Jersey, 1976.

POLLETE, M. e PAGETTI SILVA, L. Gesamp Icam e PNGC - Análise comparativa entre as metodologias de gerenciamento costeiro integrado. Revista da Sociedade Brasileira para o Progresso da Ciência, nº4 Tema e Tendências: Gestão das Águas, 2003, p. 27-30.

SORENSEN, J. Baseline 2000. Background Report: The Status of Integrated Coastal Management as an International Practice. Second Iteration. Dispoível em: www.czca-azcc.org/baseline2000.pdf. Acessado em junho de 2005.

VALLEGA, P.G.E.F Agenda 21 of Ocean Geography. In: A. VALLEGA, P.G.E.F AUGUSTINUS \& H.D. SMITH (ed.): Geography. Oceans and coasts towards sustainable development. Franco Angeli, 1998.

Trabalho enviado em fevereiro de 2009

Trabalho aceito em agosto de 2009 